HISTORIA

\title{
EROTISMO, SÍMBOLOS CULTURALES Y JUSTICIA SOCIAL EN LA OBRA PICTÓRICA DE CARLOS ENRÍQUEZ
}

EROTICISM, CULTURAL SYMBOLS AND SOCIAL JUSTICE IN THE PICTORIAL WORK OF CARLOS ENRÍQUEZ

ㅁ Osvaldo Hernandez González Diana Rosales-Pla 
RECIBIDO: $15 / 12 / 2020$

ACEPTADO: $1 / 08 / 2021$

ACEDTAD: $1 / 08 / 2021$

\section{RESUMEN}

En este artículo se analiza la obra del artista cubano Carlos Enríquez, subrayando los elementos simbólicos y los aspectos más relevantes de su estilo pictórico y de su concepción del mundo. Lo preclaro y revolucionario de sus ideas artísticas nos permite vincularlas de manera crítica con problemáticas sociales del presente. Los documentos publicados en revistas indexadas sobre los artistas plásticos del llamado "arte de vanguardia" en la pintura cubana, han sido bastante pobres y limitados. En este sentido, explorar el universo de la obra de Carlos Enríquez, haciendo hincapié en los elementos eróticos y simbólicos que habitan en ella, puede contribuir a que los jóvenes cubanos se enriquezcan culturalmente, se empoderen con una visión cítrica de la realidad social en la que se desenvuelven y al mismo tiempo, recobren algo que al parecer se ha ido perdiendo con el hechizo de la globalización: la sensibilidad en la narrativa popular del erotismo y el amor por lo nacional.

\section{PALABRAS CLAVE}

\section{Erotismo, Pintura cubana, Arte de vanguardia}

\section{A B S T R ACT}

This article analyzes the work of Cuban artist Carlos Enríquez, highlighting the symbolic elements and the most relevant aspects of his pictorial style and his conception of the world. The illustrious and revolutionary of his artistic ideas allows us to link them critically with social problems of the present. The documents published in indexed magazines on the plastic artists of the so-called "avant-garde art" in Cuban painting have been quite poor and limited. In this sense, exploring the universe of Carlos Enríquez's work, emphasizing the erotic and symbolic elements that inhabit it, can contribute to the cultural enrichment of young Cubans, empowering themselves with a citrus vision of social reality in the that unfold and at the same time, recover something that seems to have been lost with the spell of globalization: sensitivity in the popular narrative of eroticism and love for the national.

\section{KEYWORDS}


Qué es el arte, sino el modo más corto de llegar al triunfo de la verdad, y de ponerla a la vez, de manera que perdure y centellee en las mentes y en los corazones.

José Martí.

Carlos Enríquez (1900-1957), artista plástico cubano del siglo XX, es considerado un destacado representante de la historia del arte cubano, que por los albores de 1925 rompió con la rigurosidad del academicismo para crear un estilo nuevo dentro de la pintura cubana. Fue pintor y escritor. A pesar de haber conocido bien los movimientos de la pintura en Europa, se inspiró en lo rural y en los símbolos que componen la memoria colectiva de los cubanos para crear un mundo de imágenes habitado por elementos culturales nacionales. El erotismo inherente a sus obras se diluye con maestría por un vasto universo colorido, en una expresión rebelde que pretende aspirar a la provocación resistiéndose a la vulgarización, con constantes movimientos por una realidad que exacerba los problemas sociales.

De acuerdo con los criterios de Toledo, de la Hoz \& Castañeda (2019), la cultura cubana atraviesa por una pérdida de valores que lacera las normas de convivencia y vulgariza, en algunos casos por medio del arte, el erotismo que habita inherentemente en las creencias y la identidad cultural de los cubanos. Como antídoto a esta realidad ineluctable, rescatar y promover la obra de Carlos Enríquez es una oportunidad para navegar por un universo simbólico que se expande desde lo rural a lo histórico con mucha creatividad. Esta experiencia genera escenarios en los cuales las leyendas, lo cotidiano y los símbolos nacionales, se yuxtaponen o cobran vida propia, eso sí, con un erotismo compartido por los elementos que danzan entre colores y líneas para dar cuerpo a un escenario visual autóctono.

La historia del arte reclama un permanente diálogo con las problemáticas del presente y mediante la apreciación valorativo-crítica de la obra de artistas que marcaron una época, podemos darle respuesta. Este ensayo se apropia de la obra de Carlos Enríquez subrayando elementos propios de su comunicación visual, entrelazándolos con las realidades que emergen en condiciones del desarrollo social contemporáneo, sobre todo con la crisis de valores que golpea la sociedad cubana. Al rescatar y destacar la obra de Carlos Enríquez y los elementos sensuales que habitan en ella, se espera que los jóvenes cubanos de hoy se reconozcan culturalmente y al mismo tiempo recobren, algo que al parecer se ha perdido en el hechizo de la globalización: la sensibilidad en la narrativa del erotismo y el amor por los símbolos nacionales.

\section{UNA APROXIMACIÓN A LA VIDA, OBRA Y MUERTE DE CARLOS ENRÍQUEZ: \\ EL PINTOR DE LAS BALADAS CUBANAS}

En agosto de 1900 nació Carlos Enríquez en el pueblo de Zulueta, en la histórica provincia de las Villas (conocida en la actualidad como Santa Clara), una de las seis provincias del centro del archipiélago cubano. Inicia estudios en su ciudad natal, pero después se traslada a la ciudad de La Habana para realizar el bachillerato. Una vez en plena edad universitaria, con la ayuda de sus padres, viaja a los Estados Unidos para estudiar la carrera de Ingeniería. Muy pronto se aparta de las ciencias básicas y se muda a Philadelphia para inscribirse en la Escuela de Bellas Artes de Pensilvania, donde su carácter rebelde y la sagacidad de su valoración estética lo colocan en repetidos problemas con las autoridades de la academia, lo cual concluyó en su expulsión.

En la Escuela de Bellas Artes de Pensilvania se enamora de la pintora norteamericana Alice Neel, la cual en sus retratos expresionistas combinaba líneas, colores y emociones con innovación y originalidad. Vienen a La Habana en 1925 y emprenden una vida matrimonial, la cual pasa por muchos problemas, incluyendo la muerte de la primera de sus hijas (Santillana del Mar, la cual llamaron así en honor a la localidad ibérica), siendo aún muy pequeña. En muy poco tiempo se separan, puesto que Carlos Enríquez sale de la relación abruptamente, y eso llevó al hoy considerado ícono de la pintura americana a cometer varios intentos de suicidio, por lo que tuvo que ser hospitalizada más de una vez (Hoban, 2010).

Alrededor de 1927, en el II Salón de Bellas Artes y en la Exposición de Arte Nuevo en La Habana, comienzan el público y los críticos de la época a relacionarse con sus obras con recelo 
y nerviosismo, puesto que la osadía e inclinación de Carlos Enríquez por el desnudo resultaría controversial para el momento histórico de la Isla, marcado por la consolidación del sistema neocolonial (Lecuona, 1993; Pini, 2000). En esta época realiza nuevamente un viaje a los Estados Unidos y después se mueve por muchos países de Europa, donde se relaciona con distintos movimientos pictóricos, en especial con los conceptos y valores del surrealismo, lo cual resulta clave para darle luz propia al vanguardismo inherente de su obra (Bombino, 2015).

De vuelta a La Habana en 1934, hace lo posible porque sus cuadros puedan exponerse en la Asociación de Reporteros de La Habana, pero el erotismo que habita en ellos es la coartada ideal para las rígidas valoraciones de la época y con palabras como "inmorales o poco decoro" juzgan las obras y no autorizan la exposición. En relación a ello Carpentier (1973) escribió, "solo podemos desear a Carlos Enríquez que permanezca el mayor tiempo posible en una ciudad en que los burgueses no se dejan epatar y en que su obra es acogida con la comprensión y el respeto que le fueron negados en su país". (p. 257) No obstante, muy pronto "El rey de los campos de Cuba", obra inspirada en el revolucionario Manuel García Ponce, recibe los aplausos de la crítica.

En lo adelante, le daría vida a un universo de imágenes que le valieron para ser considerado uno de los artistas más notables de la plástica cubana y un representante por excelencia del llamado "arte de vanguardia». En el Museo Nacional de Bellas Artes de Cuba se exhiben al público un cúmulo de obras como, por ejemplo: "Detalle de la muerte de Martí", "Boceto para Virgen del Cobre", "Combate", "El héroe criollo", "María Luisa en el Ariguanabo", entre otras. Los problemas de salud y el alcoholismo problematizaron los últimos momentos de su existencia personal, dejándolo solo y lejos de los que más le importaban. Carlos Enríquez murió en La Habana, el 2 de mayo de 1957, pero legándonos un estilo rebelde y autóctono que rompió con el academicismo y las concepciones estrictamente técnicas de la época.

\section{LAS PALMAS, LOS CABALLOS Y LA COTIDIANEIDAD DE LA VIDA RURAL: SÍMBOLOS DE CUBANÍA E INSPIRACIÓN}

Para enarbolar la bandera del modernismo, convertirse en un creador de vanguardia y desarrollar una producción artística divorciada de lo convencional y lo costumbrista, Carlos Enríquez estuvo dispuesto a recibir los embates de los partidarios de la academia de la época. Es por ello que, al abrazar la rebeldía artística como antídoto a lo establecido por la crítica, se decidió a crear una corriente pictórica y aún más, legitimarla en la historia del arte cubano. Esta es El Romancero Guajiro, como la bautiza en su publicación "El criollismo y su interpretación plástica" de 1934 (Anreus, 2020). Muy cercano a lo que hoy se conoce como artist's statement (ver discusión en Singh, 2018), pone de relieve una concepción del mundo díscola, orientada a la subjetividad del entorno y sus personajes, a sentir la emoción del paisaje y dejar en el lienzo la huella de la experiencia esotérica individual, en lugar de la representación naturalista de lo observado.

En este sentido, si bien Carlos Enríquez había estado relacionado con los estilos pictóricos vanguardistas de los Estados Unidos y Europa, existen varios aspectos de apropiación personal que hacen soberana su paisajística y la convierten en una expresión auténtica dentro de la plástica latinoamericana. De acuerdo a los criterios de Martínez (2010), el mismo artista describía que su método consistía en trazos suaves y cuerpos físicos transparentes que se mezclan sin renunciar a su esencia. La luz atraviesa la materia y se adueña del espacio: el entorno transmuta en un sistema vivo, sensual y caprichoso donde la relación del guajiro con su medio vernacular cobran relevancia. La importancia de estos elementos parte de su experiencia mientras cuidaba los negocios de sus padres por el interior de la Isla, lo cual le permitió redescubrir el campo y la ruralidad con sus respectivos encantos. Así, la belleza o cualidad artística de las cosas se encuentra en su dimensión mítica, en su sentido más primitivo. Sus obras desencadenan un cinetismo visual único dentro de la historia de la pintura cubana (Iglesias, 2020). De alguna manera pudiéramos decir que esta experiencia desemboca en un proyecto original y perspicaz de rescate cultural.

El Romancero Guajiro tiene su génesis en la colección de poemas de Federico García Lor- 
ca "Romancero Gitano", es la adaptación cubana de ciertos preceptos vanguardistas europeos que imbrican expresionismo y surrealismo. En el caso cubano, Carlos Enríquez pretende contribuir al desarrollo del gusto por el campesino y su paisaje "rodeado de ese algo misterioso y fantástico que puebla su soledad con curiosas leyendas que surgen de su contacto directo con la tierra que, como los muertos, produce fosforescencia" (Martínez, 2010, s/f). Sobre la concepción de sí mismo como un creador de mitos, Carlos Enríquez emplea un amplio repertorio de símbolos destinados a movilizar la sensibilidad del público habanero y el mercado internacional. Dentro de esta categoría se encuentran obras como "Paisaje criollo", "Cabeza de caballo" y otros lienzos de singular sensualidad y movimiento.

Ahora bien, su inclinación por los campos de Cuba y las historias que allí se presentan poseen como contraparte la esplendorosa dinámica de la urbe habanera, a la cual considera alienada, híbrida y sin responsabilidad nacional (Martínez, 2010). Todo ello se traduce como características comunes de las capitales mundiales, donde los adelantos científicos, los centros de entretenimiento, las academias y tradiciones son compartidas y disfrutadas por un público multinacional. Sin embargo, este rechazo la hibridación cultural es comprensible si tenemos en cuenta el movimiento filosófico y artístico que Carlos Enríquez se suscribe y asume como parte de su propia identidad. El modernismo en Latinoamérica o americanismo, independientemente de la influencia francesa y española importada, destacó por su capacidad para asimilar como autóctonas las distintas expresiones de la cultura extranjera. Al respecto, resultan interesantes los apuntes de Federico de Onís: "El americano siente como suyas todas las tradiciones sin que ninguna le ate al pasado, (...) sabe que América es hija de Europa y que al mismo tiempo no es Europa (...). De ahí que la extranjerización del Modernismo hispanoamericano fuera más bien expresión de su cosmopolitismo nativo, de su flexibilidad para absorber todo lo extraño sin dejar de ser el mismo" (Castillo, 1974, p. 71-72).

Las provincias de Cuba se vieron, en proporciones variables, menos invadidas por estas influencias, lo que condujo a una especie de adoración por parte del pintor modernista hacia lo que se mantiene intacto, con énfasis en su fugacidad y simpleza. Sobresale en su obra el empleo de la imagen simbolista (Medina, 1995), uno de los primeros recursos en el modernismo que se despojó de las concepciones alegóricas tradicionales. En este movimiento, los símbolos evocan el rechazo a la sociedad burguesa industrializada, el retorno a lo espiritual, a lo autóctono y a un entorno concebido desde el mundo interior del artista. Resultan recurrentes en Carlos Enríquez la recreación de paisajes que reflejan estados de ánimo con un evidente respeto por el culto a la belleza y la forma. La obra "Paisaje criollo", representa con un tratamiento de la luz que recuerda a los impresionistas, su favoritismo por la sensualidad de la campiña. Evidentemente, la inclinación por la pureza y el nacionalismo que perseguía Carlos Enríquez no ha reencarnado en los pintores contemporáneos de la Isla.

En este sentido, la problemática de la emigración es una de las influencias recurrentes en las obras pictóricas nacionales. Con la contemporaneidad, ciertas dinámicas transformaron las maneras de crear; temas como la denuncia social, el paisaje urbano, el movimiento cosmopolita y las influencias del abstraccionismo han modificado el rumbo de las artes visuales. Un elemento importante ha sido el factor económico y la creación de un mercado destinado en su mayoría no al público nacional, sino al consumo extranjero. La simbología actual dista mucho en su dimensión semántica de la cosmovisión modernista. A un ambiente cubano más rápido, globalizado y permeado por adelantos tecnológicos que se suceden de manera exponencial, le corresponden artistas con un conjunto de valores distintos. Entre ellos, la predilección por lo foráneo en momentos en los que gran parte de la producción pictórica cubana ha encontrado asilo y hogar en Estados Unidos y Europa, mientras la censura y la pobreza moral y discursiva ocupan el espacio vital de la libertad de expresión en la Isla. 


\section{LA MUJER CRIOLLA COMO BANDERA POR EXCELENCIA DE LA CUBANÍA: HISTORIAS DE OPRESIÓN Y JUSTICIA SOCIAL}

Sin lugar a dudas, los derechos de las mujeres han ido progresando como resultado de una lucha histórica, sin ser resueltos completamente (Jacquemart, 2017). En la actualidad, en Cuba predomina en el campo político una narrativa que promueve que las personas de este género ocupen lugares protagónicos en la vida social, económica y política de la nación (Díaz, Castro, Mestre, González, Torres \& Castro, 2017). Sin embargo, con la participación cada vez más hegemónica de los géneros musicales urbanos y de manera especial, en los espacios visuales que protagonizan los jóvenes creadores de la plástica, la mujer cubana es desvalorizada y constantemente reducida al plano sexual, exacerbando sus características corporales. Como alternativa a esta realidad que se amalgama con la pérdida de valores (y una alarmante debilidad por demeritar lo nacional y ensalzar lo extranjero) por la cual atraviesa la nación, observar la obra de Carlos Enríquez es recobrar el erotismo simbólico que se expande en un imaginario de justicia $\stackrel{\infty}{N}$ propio sin perder la conexión con lo histórico y lo nacional.

․ Carlos Enríquez no solo hizo un acuerdo moral y artístico con lo autóctono para darle participación a los símbolos nacionales como la Palma Real y la luz del trópico. En el mismo sentido, mediante un pensamiento preclaro y revolucionario para la época, convierte a las mujeres cubanas en protagonistas de los hechos sociales, elevándolas al plano del reconocimiento público. Hay que subrayar una vez más que su pincel virtuoso y rebelde sería cuestionado por sus contemporáneos puritanos y academicistas, puesto que el cuerpo femenino en sus obras sería representado con un realismo que coquetea con lo onírico. En "Las tetas de la guajira" (Fig. 1), por ejemplo, nos representa el modelo cultural de la época, donde la mujer criolla, si bien es el corazón de todo lo que orbita en el mundo campestre, queda enquistada en las labores domésticas sin poder desplegar su potencial creativo y social.

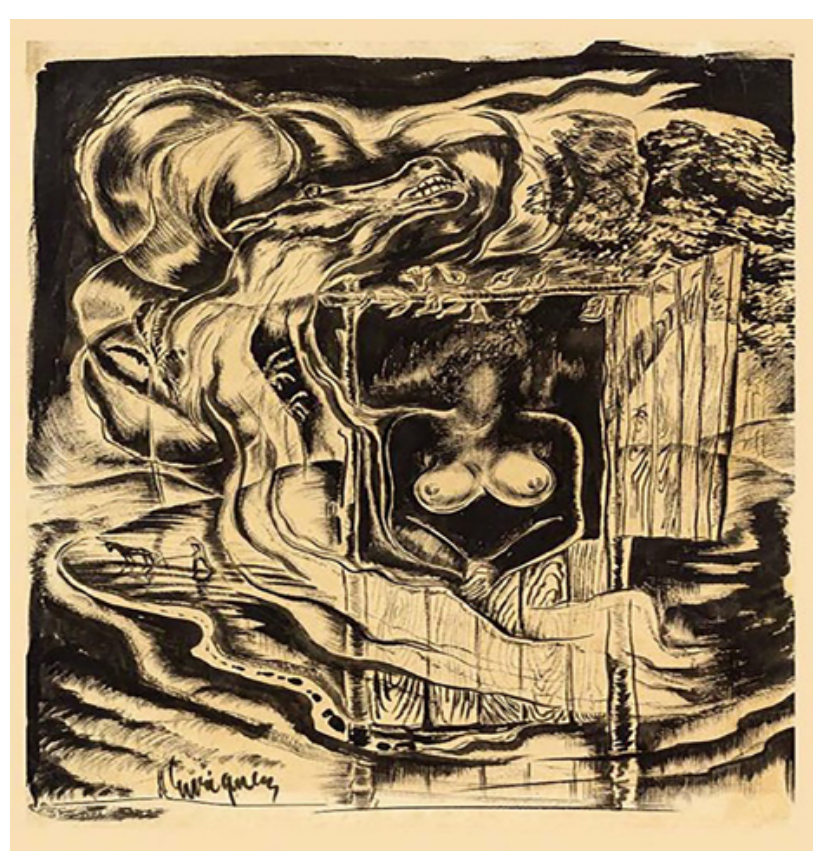

Fig. 1. Las tetas de la guajira, 1930 Museo Nacional de Bellas Artes de Cuba

En la realidad cubana de hoy, aunque existen minúsculas alternativas de cambios y proyección social, tanto para el mundo del arte como para la práctica política y laboral, aún persisten un panorama donde la violencia de género y las libertades sexuales son reprimidas o azotadas de manera explícita o implícita, por una amplia gama de opiniones prejuiciosas (García, 2019). Una vez más Carlos Enríquez rivaliza con la realidad opresora de su época y pavimenta mediante su obra pictórica un camino que desborda el marco de su existencia personal y alcanza las problemáticas actuales. En imágenes como "Bilitis" (Fig. 2), por solo mencionar una, aborda la problemática de la discriminación hacia la población homosexual, quienes en relación a las dinámicas sociales opresoras de la libertad individual han vivido luchando contra la arbitrariedad, el escozor de prejuicio y la insolencia. 


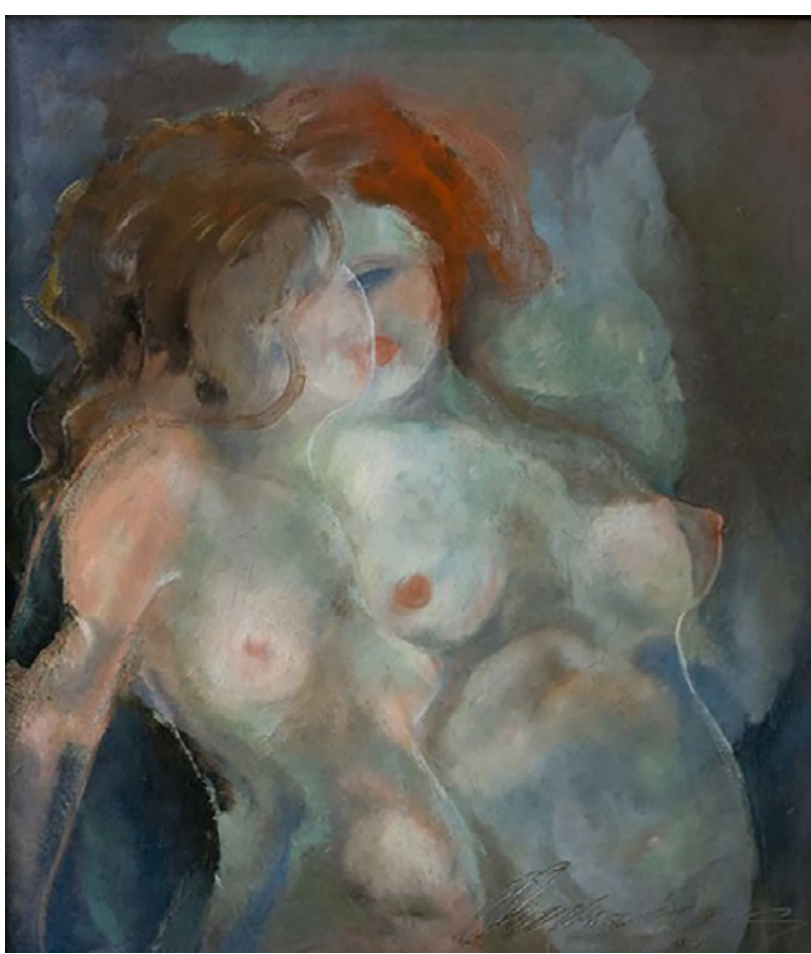

Fig. 2. Bilitis, 1935

Museo Nacional de Bellas Artes de Cuba

La sensibilidad de Carlos Enríquez no se limita a la exposición de la homosexualidad en una época conservadora, sino a la representación artística como expresión de la belleza inherente a la libertad humana. Es por ello que en estas imágenes el movimiento desordenado y sinuoso de las líneas y la sensualidad de los colores y emociones se amalgaman sobre la orientación sexual lésbica dándole espacio en la sociedad a las historias que allí habitan y se desarrollan. Sin lugar a dudas, el mérito del preclaro pensamiento del artista radica en simbolizar, con esa mágica mezcla de realismo y surrealismo, la diversidad sexual como algo común. Lo cual desborda las problemáticas de su época y contribuye a la "aceptación" de la homosexualidad en la sociedad cubana de hoy. Simplemente recordemos que las iglesias evangélicas de Cuba y parte importante de la sociedad, protestaron en la última Asamblea Constituyente (24 de febrero de 2019) contra la legalización del matrimonio homosexual, poniendo de relieve el soberbio machismo que aún impera en la cultura cubana.

No obstante, el habitual y audaz tratamiento del desnudo en su quehacer pictórico alcanzaría su máxima expresión en una obra que denuncia la violencia contra las mujeres: "El rapto de las mulatas" (Fig. 3). La obra se apoya en historias arquetípicas del arte-como por ejemplo el rapto de Europa, de las hijas de Leucipo o de las Sabinas-, pero la recontextualiza a la historia de los cubanos. Esta una de las obras más estudiadas y elogiadas en el campo de las artes plásticas cubanas. No sólo por la sensibilidad, la riqueza de su colorido y la rebeldía de la técnica empleada, sino también, por su capacidad para poner de relieve mediante elementos eróticos una época convulsa y procelosa de la historia nacional. La escena combina sensuales vínculos entre hombres, mujeres y caballos donde la luz del trópico y el vaivén de las palmas se revientan presenciando un hecho de abuso insólito. Así, sobre la base de pinceladas agitadas, veladuras y transparencias el movimiento y la sensualidad cobran luz propia. En la actualidad, se exhibe al público en el Museo Nacional de Bellas Artes.

Más allá de la excelencia en la representación artística, la escena denuncia la violencia contra las mujeres en el mundo rural cubano en época de revolución, lo cual aún en la actualidad continúa siendo un problema ineludible, aunque invisibilizado (Poll, Alonso \& Mederos, 2012). Habría que subrayar que la violencia a la mujer puede darse en una amplia variedad de circunstancias y la compleiidad del fenómeno (Ver discusión en Yugueros, 2014) desborda la cultura de la Isla. En el plano internacional se proclama que la violencia contra la mujer es una problemática de Salud Pública y de Derechos Humanos que implica la organización de políticas concertadas de los gobiernos (Winter etal., 2016). Lo clave aquí es como Carlos Enríquez en una época clasista y puritana utiliza elementos simbólicos propios de su obra pictórica, para denunciar las prácticas inmorales de un contexto determinado, aunque paradójicamente serían sus obras las que tildarían los críticos de "inmorales, impropias y obscenas". 


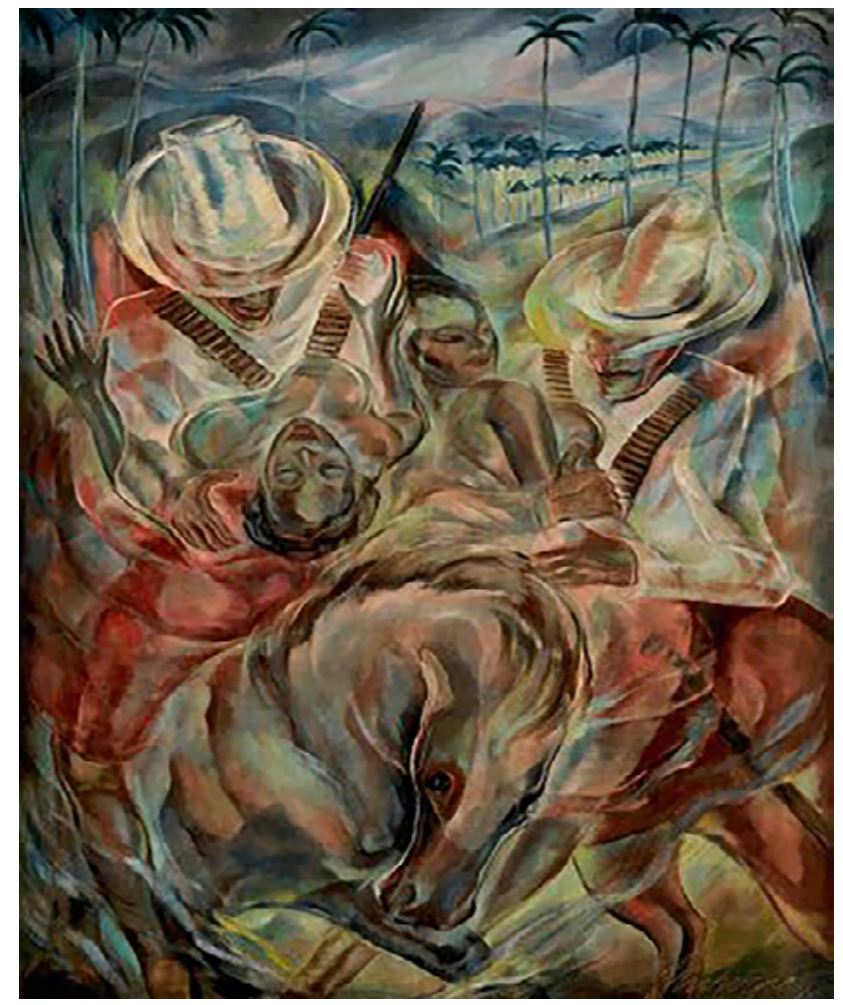

Fig. 3. El rapto de las mulatas, 1938 Museo Nacional de Bellas Artes de Cuba

No se podría honrar el papel de la mujer en la obra pictórica de Carlos Enríquez en un espacio escritural tan breve como este y por ello le recomendamos al lector relacionarse con cuadros como, por ejemplo: "Eva en el baño", "Mujeres junto al río", "Desnudos", "María Luisa en el Ariguanabo", "Retrato de María Luisa Gómez Mena", "Dama en Carrusel", "Desnudo de Mujer", "Desnuda", "Retrato de Fernande Lescot", "Retrato de Joven", "Dos Mujeres en la Cama", entre otras. Sobre la base de lo dicho, lo que hemos tratado de hacer en este apartado es poner de relieve el pensamiento inclusivo y abierto del artista. Y también la valentía e inclinación por la denuncia social y ese soberbio e inapelable sentido de cubanía que recoge las leyendas del campo y la imagen de bandidos en época de revolución, siempre envueltos en un estilo único e irrepetible donde el erotismo y la sensualidad de la mujer son su esencia.

\section{LA CAÍDA EN COMBATE DEL HÉROE NACIONAL DE CUBA: HISTORIA DE SOBERANÍA E IDENTIDAD NACIONAL}

Sin lugar a dudas, la imagen del José Julián Martí y Pérez, es clave en la memoria colectiva de los cubanos, puesto que su trascendencia intelectual le dio y le dará luz y unidad a nuestro pueblo (Escribano, Olivia, Boulet \& Hinojosa, 2020). Es por ello que el apóstol ocupa un puesto primordial en muchas de las pinturas de Carlos Enríquez que recogen relatos históricos. En "Dos Ríos" (Fig.4), utiliza símbolos recurrentes en su obra como, por ejemplo: los caballos, el viento, el erotismo y la sinuosidad de pinceladas sueltas, para representar el momento de la caída en combate de Martí, luchando por la libertad y la soberanía de la nación. En la escena es palpable un caballo desbocado y asustadizo que se disuelve en el movimiento, la angustia y la conmoción en el rostro del apóstol, y en su auxilio dos siluetas femeninas desdibujadas, emocionadas y traslúcidas que ayudan al revolucionario caído por los embates del enemigo.

En muchas obras de arte, los pintores surrealistas han explorado el erotismo y la muerte como impulsos primarios de exceso (Gritzner, 2010). Carlos Enríquez, heredero de la escuela del surrealismo, se vale de la expresión onírica y subjetiva que la caracteriza y a la vez del realismo histórico, para brindarle a los anales del arte cubano el hecho de Dos Ríos desde una perspectiva renovada y etérea. La muerte y la violencia como hechos elicitadores de angustia y miedo por excelencia, aparecen envueltos por la solidaridad, la sensualidad y el apoyo emocional. A su vez, el misticismo del imaginario rural cubano soporta las embestidas del pensamiento creativo, situando la problemática y su inherente sentido de lucha y liberación en el inconsciente colectivo del pueblo cubano. Así, la caída del apóstol no se vuelve un hecho lamentable, más bien es una reconceptualización espiritual de la continuidad. 


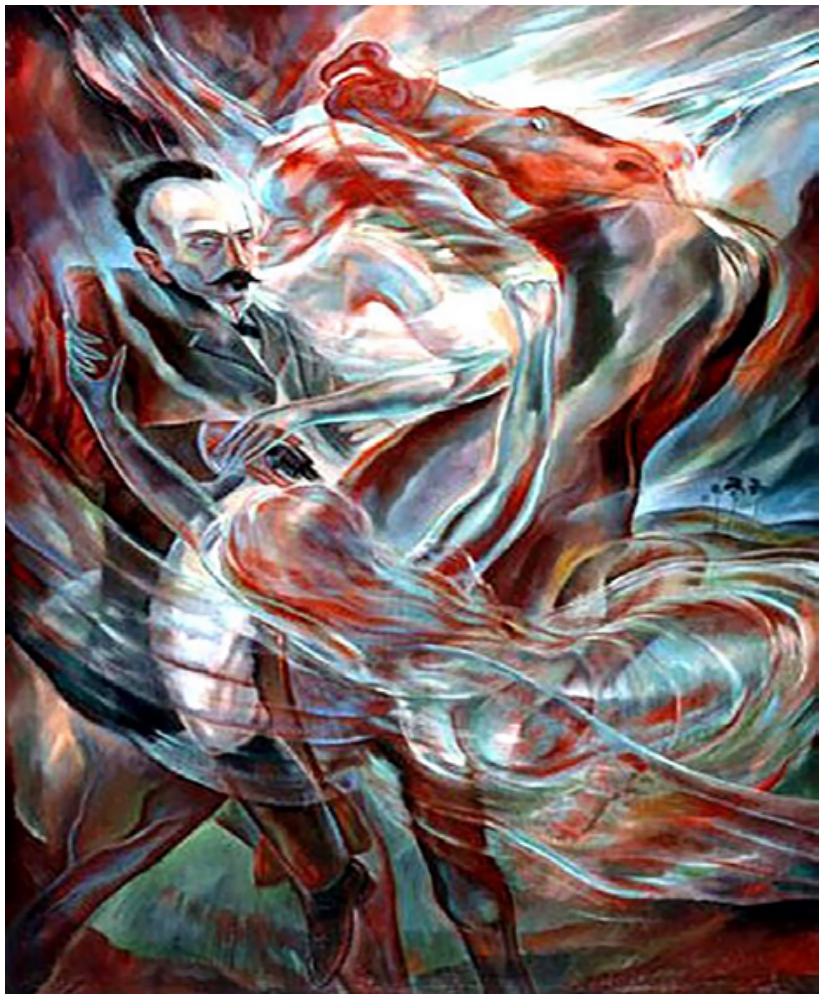

Fig. 4. Muerte en Dos Ríos, 1952 Consejo de Estado de la República de Cuba

De acuerdo con los criterios de Pentón (2018), es posible que Carlos Enríquez haya tratado de ilustrar uno de los pensamientos martianos sobre la muerte: "La vida se ha de llevar con bravura y a la muerte se le ha de esperar con un beso". Separándose así de las representaciones de la caída en combate de José Martí de otros artistas como, por ejemplo, Alicia Leal, Juan Vicente Rodríguez Bonachea y Esteban Valderrama. Ya que actualmente la sociedad cubana atraviesa por una crisis de valores cuya solución no parece ser un hecho que pueda producirse a corto o mediano plazo. Es más vital que nunca promover la obra y acción republicana del apóstol, como apoyo moral y conductual para los jóvenes cubanos de hoy. En este sentido, la obra de Carlos Enríquez es una excelente oportunidad de crecimiento cultural y moral, puesto que la raigal cubanía que envuelve la práctica pictórica del artista, pueden potenciar el sano nacionalismo y el sentimiento honorable por nuestra historia.

\section{DEL IDILIO A LA REALIDAD: LA CRUDA DENUNCIA DEL ROMANCERO GUAJIRO}

Carlos Enríquez creció rodeado de posibilidades económicas, el padre que se convirtió en médico del militar y político cubano Gerardo Machado, se permitió enviarlo a los Estados Unidos a estudiar Contabilidad y Comercio (Bianchi, 2020). Sobre la base de la historia y posición de los progenitores, las aspiraciones se centraban en preparar un camino de bonanza material para el heredero. Sin embargo, el instinto artístico se impuso y el autor del Romancero Guajiro decidió abrazar el rigor de la pobreza para desarrollar su carrera como pintor y dedicó la singularidad de su talento a revolucionar el arte, en detrimento de su estabilidad económica.

De ahí que Carlos Enríquez sobreviviera con el primer empleo que estuviera disponible. Según comenta Graziella Pogolotti (2020), "desde lo alto de una ventana protagonizó una espectacular fuga para escapar a sus acreedores". (párr. 2) El artista despreciaba la moral burguesa y clasista de la isla, incluso sostenía una relación convulsa con sus acomodados padres. Cuando estos mueren, recibe una herencia y con ese dinero sobrevive por un tiempo hasta que su instinto de autodestrucción, su condición de alcohólico y las dolencias del cuerpo (resultantes de continuas fracturas en el cráneo y las piernas) mellaron su capacidad para crear arte.

El rechazo a la burguesía cubana y la preocupación por los males enraizados en las zonas rurales del país a causa de un desarrollo económico desigual que favorecía a La Habana, fueron expresados con fuerza en la obra "Campesinos felices" (Fig. 8) de 1938. Si bien Carlos Enríquez creó pinturas de elevada sensualidad e intenso movimiento, producto de su condición de ferviente enamorado del criollismo y sus peculiaridades y de la pasión estética típica de los modernistas, esta pieza se convierte en la antítesis de su propia línea de creación. Al valorar cítricamente la obra en contexto, en un personaje de elevado sentido de cubanía como lo fue Carlos Enríquez, es comprensible que se desarrollara con efervescencia tal necesidad de denunciar crudeza de las condiciones de vida en ciertas zonas rurales. Para 1938, una serie de importantes acontecimientos de singular impacto histórico habían acaecido: fue la época de la Revolución del 30. 
El 20 de mayo de 1929 concluyó legalmente el mandato presidencial de Gerardo Machado, sin embargo, a causa de modificaciones realizadas a la Constitución de 1901, se estableció que el mismo podía continuar, en caso de ser reelegido, hasta 1935 (Martínez, 2020). El espurio suceso fue conocido como la Prórroga de Poderes y detonó el descontento popular en el seno de una revolución que ya se gestaba. A partir de este momento, una tormenta de inestabilidad política y repetidas intervenciones por parte del gobierno norteamericano se abalanzaron sobre una isla que ya había sufrido el impacto económico de la crisis de 1929. 1933. La pobreza era una realidad eminente que Carlos Enríquez no pasaría por alto, y con mayor sobriedad en las pinceladas, pero sin perder la inclinación por el erotismo como recurso pictórico. En "Campesinos felices" (Fig. 5) la denuncia alcanza su máxima expresión en solidaridad con las personas más necesitadas.

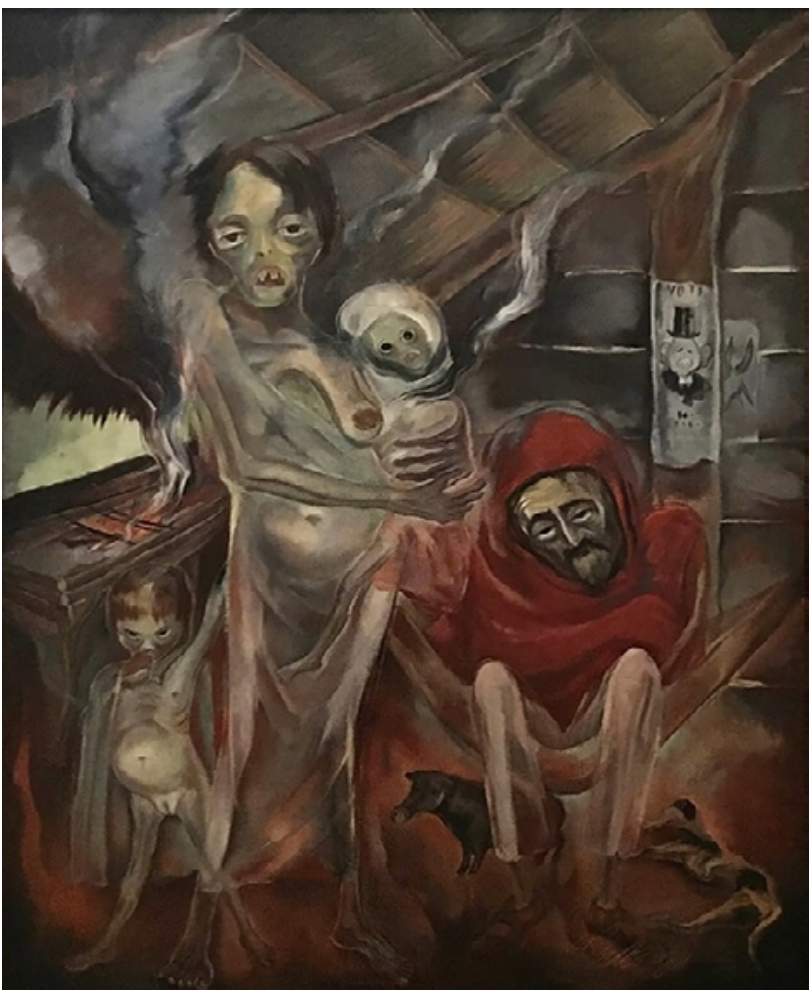

Fig. 5.

Campesinos felices, 1938. Museo Nacional de Bellas Artes de Cuba

Carlos Enríquez se opuso a lo burgués y convencional subrayando la belleza de la vorágine mítica del entorno campestre cubano. Por ello resulta de marcado interés la obra "Campesinos felices", por su discurso agreste que refleja una realidad brusca: una familia rural desnutrida, famélica y desdentada, en una casa de paupérrimas condiciones donde las enfermedades se reparten por igual a niños y adultos; el rostro de la pobreza extrema pintada sin tapujos (Herrera, 2020). La variedad cromática refuerza la escena lóbrega y mustia y el tratamiento de los colores advierte, a pesar de la mirada distinta, que es una obra creada por Carlos Enríquez. Sin ropas, con macotas muertas de hambre, utilizando la desnudez como escudo ante el clima y con un bohío que amenaza con caer sobre sus cabezas, se expone la estampa de una realidad que el pintor, en su esencia rebelde, quiso compartir con su país y con el mundo.

La Cuba del siglo XXI ha visto crecer a artistas comprometidos con su tiempo y las problemáticas de su sociedad, pero a causa de los preceptos de censura establecidos por un poder político que evoca al Gran Hermano, los ha visto partir en su quimera por la libertad de creación. La proyección del gobierno cubano actual, desde el punto de vista comunicativo, ha resultado poco flexible. A lo largo de la época revolucionaria, el desarrollo cultural ha estado sujeto a un marco legal que limita la creación cuando problematiza derechamente las normas impuestas por el poder político. Las exposiciones en galerías estatales son monitoreadas y su contenido está sujeto a la interpretación de evaluadores que responden a los dictados gubernamentales.

El estilo y la soberanía artística de Carlos Enríquez en épocas históricas donde la censura (expresada desde otros ángulos represivos como el excesivo clasismo, inherente al neocolonialismo) también era habitual, se vuelve un robusto ejemplo para la sociedad cubana de hoy, en especial para los jóvenes artistas que deberían comprometerse con la denuncia social y la libertad. Desde esta perspectiva, se pudiera decir que el pintor de las baladas cubanas era un cronista por excelencia, un relator de historias crudas y reales envueltas en sueños propios.

\section{CONCLUSIONES}

La riqueza visual de la obra de Carlos Enríquez, su interés por las leyendas del campo, los símbolos nacionales, la sensualidad y el coraje para poner de relieve las problemáticas de la época, lo convierten en uno de los maestros históricos del arte cubano. La saga- 
cidad de su pensamiento nos ayuda a explorar la memoria colectiva del pasado cultural de nuestro pueblo y a la vez sirven de fuerza inspiracional para afrontar a los conflictos del presente. El universo de imágenes del artista es, en otras palabras, una lección de cubanía para aquellos que han olvidado el valor de la historia nacional seducidos por la narrativa de la globalización. Y al mismo tiempo se vuelve un antídoto para los que buscan oprimir la libertad de creación. Es por ello que valorar de manera crítica su obra es necesario para la cultura cubana de hoy.

\section{REFERENCIAS}

Anreus, A. (6 de agosto de 2020). Carlos Enríquez y su Romancero Criollo. Cubaencuentro. Recuperado de https:// ww.cuebaencuentro.com/cultura/articulos/carlos-enriquez-y/su/romacero-crio$\underline{\text { lo-248048 }}$

Bianchi, C. (6 de agosto de 2020). Romancero criollo de Carlos Enríquez. Juventud Rebelde. Recuperado de https://progresosemanal.us/21 160725/romancero-criolo-carlos-enriquez/

Bombino, A. O. L. (2015). Alejo Carpentier y su acercamiento a Carlos Enríquez y Alejandro García Caturla: una defensa de la identidad cultural cubana y latinoamericana. Islas, (178), 233-244.

Carpentier. A. (1973). Crónicas. Editorial Arte y Literatura.

Castillo, H. (1974). Estudios críticos sobre el modernismo. En Sobre el concepto del modernismo (pp 71-72). Gredos, Madrid.

Díaz Cuellar, Fé E, Castro Gutiérrez, Esther, Mestre Oviedo, Josefina, González Landrián, Lázara, Torres Cancino, Indira, \& Castro Alonso, Moisés. (2017). La mujer cubana: evolución de derechos y barreras para asumir puestos de dirección. Revista Médica Electrónica, 39(5), $1180-1191$.

Escribano, E., Oliva, N., Boulet, R., \& Hinojosa, Y. (2020). La obra de José Martí en la formación inicial y permanente de los educadores cubanos. Revista Cubana de Educación Superior, 39(1), e9. Epub 01 de abril de 2020. Recuperado en 20 de agosto de 2020, de http://scie- lo.sld.cu/scielo.php?script=sci arttext\&pi$d=$ S0257-43142020000100009\&ln$\mathrm{g}=\mathrm{es} \&$ tlng $=$ es.

García, Y. (2019). Violencia de género, feminismo y representación en Cuba. Revista Estudos Feministas, 27(1), e53719. Epub April 08, 2019.https://doi.org/10.1590/18069584-2019v27n153719

Graziella, P. (22 de agosto de 2020). Hurón Azul. Granma. Recuperado de http:// www. granma.cu/opinion/2020-08-16/huron-azul-16-08-2020-21-08-07

Gritzner, K. (Ed.). (2010). Eroticism and death in theatre and performance. Univ of Hertfordshire Press.

Hernández, E. (23 de agosto de 2020). ¿¿Qué es el decreto 349 y por qué los artistas cubanos están en contra? Letras Libres. Recuperado de https://www.letraslibres.com/ mexico/cultura/que-es-el-decreto-349-ypor-que-los-artistas-estan-en-contra /

Herrera, N. (2020, 5 de agosto) Campesinos felices. islalsur. http://islalsur.blogia. com/2017/042102-campesinos-felices. php

Hoban, P. (2010). Alice Neel: The art of not sitting pretty. St. Martin's Press.

Iglesias, A. (4 de agosto de 2020). La sinuosa magia de Carlos Enríquez, a 120 años de su natalicio. Juventud Rebelde. Recuperado de http://www.juevntudrebelde.cu/cultu$\mathrm{ra} / 2020-08-03 /$ la-sinuosa-magia-de-carlos-enriquez-a-120-anos-de-su-natalicioobras

Jacquemart, A. (2017). A gendered history of the women's suffrage movement. Vingtième Siècle. Revue d'histoire, (1), 3-14.

Lecuona, O. Z. (1993). Las clases de la sociedad cubana en vísperas de la revolución. Arbor, 144(567), 135.

Martínez, J. (2010). Carlos Enríquez: The Painter of Cuban Ballads. Editor Cernuda Arte

Martínez, F. (22 de agosto de 2020). La Revolución Cubana del 30. Ruth Casa Editorial. Recuperado de https://www.ruthcasaeditorial.org/la-revolucion-cubana-del-30-ensayos-introduccion 
Medina, A. (1995). Modernismo e imagen hacia una comprensión unificada del movimiento moderno. Ensayos: Historia y Teoría del Arte, (1), 36-44.

Pentón, D. P. (2018). La muerte y el arte. Cuatro visiones de la caída de José Martí en la pintura cubana. Panorama Cuba y Salud, 13(2), 105-110.

Pini, I. (2000). En busca de lo propio: inicios de la modernidad en el arte de Cuba, México, Uruguay y Colombia 1920-1930. Univ. Nacional de Colombia.

Poll Cabrera, Meibis, Alonso Poll, Hermes, \& Mederos Avila, María Esther. (2012). Violencia contra la mujer en la comunidad. MEDISAN, 16(8), 1267-1273.

Singh, D. (2018). Artist Statement (Doctoral dissertation, Mills College).

Toledo, T., de la Hoz, M., \& Castañeda, C. (2019). Cómo valorar la supuesta crisis de valores en Cuba. ¿̇Existe realmente la crisis? Revista MéDica ElectróNica, $47(5), 105$ 117.

Winter, S., Settle, E., Wylie, K., Reisner, S., Cabral, M., Knudson, G., \& Baral, S. (2016). Synergies in health and human rights: a call to action to improve transgender health. The Lancet, 388(10042), 318-321.

Yugueros, A. (2014). La violencia contra las mujeres: conceptos y causas. BARATARIA. Revista Castellano-Manchega de Ciencias Sociales, (18), 147-159. 